\title{
A case of airway aluminosis with likely secondary pleuroparenchymal fibroelastosis
}

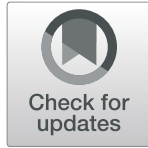

\author{
Yuki Yabuuchi ${ }^{1 *} \mathbb{D}$, Hitomi Goto', Mizu Nonaka', Hiroaki Tachi', Tatsuya Akiyama', Naoki Arai ${ }^{1}$, Hiroaki Ishikawa', \\ Kentaro Hyodo', Kenji Nemoto', Yukiko Miura', Isano Hase', Shuji Oh-ishi', Kenji Hayashihara', Takefumi Saito ${ }^{1}$ and \\ Tatsuya Chonan ${ }^{2}$
}

\begin{abstract}
Background: Excessive inhalation of aluminium powder occasionally results in upper lobe predominant lung fibrosis, which is similar to idiopathic pleuroparenchymal fibroelastosis (IPPFE) and has been suggested to be secondary PPFE.

Case presentation: A 67-year-old man who had worked in an aluminum-processing factory for 50 years visited our hospital complaining of exertional dyspnea. Chest computed tomography (CT) showed bilateral dense sub-pleural consolidation in the upper and middle lung fields, which was consistent with IPPFE; however, the possibility of secondary PPFE associated with aluminosis was not ruled out. Considering the patient's critical condition, trans-bronchial lung biopsy (TBLB) rather than surgical lung biopsy was performed, with elemental analysis of the biopsied specimen. Unfortunately, the specimen obtained by TBLB did not contain alveolar tissue; therefore, pathological diagnosis of PPFE was not possible. However, radiographic findings were highly suggestive of PPFE. On elemental analysis, excessive amounts of aluminum were detected in the bronchiolar walls, establishing a diagnosis of airway aluminosis with likely secondary PPFE resulting from aluminium exposure.

Conclusions: TBLB with elemental analysis might be useful in differentiating idiopathic PPFE from secondary causes in dust inhalation related disease, such as aluminosis. This case indicated that inhalation of aluminium might cause secondary PPFE, with attention needing to be paid to avoid further exposure.
\end{abstract}

Keywords: Interstitial pneumonia, Occupational lung disease, Trans-bronchial lung biopsy, Elemental analysis

\section{Background}

Pleuroparenchymal fibroelastosis (PPFE) is characterized radiologically by upper lobe predominant and pathologically unclassified interstitial pneumonia [1]. Most cases of PPFE have been classified as idiopathic; however, it occasionally occurs secondary to other conditions, including drug administration, infection, post-transplantation and exposure to dust [2]. In particular, there have been reports of PPFE-like lesions associated with dust exposure, such as asbestos, aluminium and aluminosilicate $[3,4]$.

In this report, we describe a putative case of secondary PPFE found in a worker exposed to aluminium dust, which was diagnosed with chest computed tomography

\footnotetext{
* Correspondence: jabberflag@hotmail.co.jp

${ }^{1}$ Department of Respiratory Medicine, National Hospital Organization, Ibaraki Higashi National Hospital, Ibaraki, Japan

Full list of author information is available at the end of the article
}

(CT), trans-bronchial lung biopsy (TBLB) and elemental analysis of the biopsied specimen. This report provides new insights into secondary as well as idiopathic PPFE.

\section{Case presentation}

The patient was a 67-year-old male non-smoker with an unremarkable past medical history. He was admitted to our hospital with a complaint of increasing dyspnea for 3 months. His parents managed a workshop in a small town, and he had worked in processing aluminum and brass to make camera parts since he was 18 years old. He did not wear a dust respirator and worked closely to the cutting machine (Fig. 1) because of his poor eyesight.

On presentation, the patient was fully conscious with a height of $160 \mathrm{~cm}$, a body weight of $47 \mathrm{~kg}$, body temperature of $36.8^{\circ} \mathrm{C}$ and percutaneous oxygen

(c) The Author(s). 2019 Open Access This article is distributed under the terms of the Creative Commons Attribution 4.0 International License (http://creativecommons.org/licenses/by/4.0/), which permits unrestricted use, distribution, and 

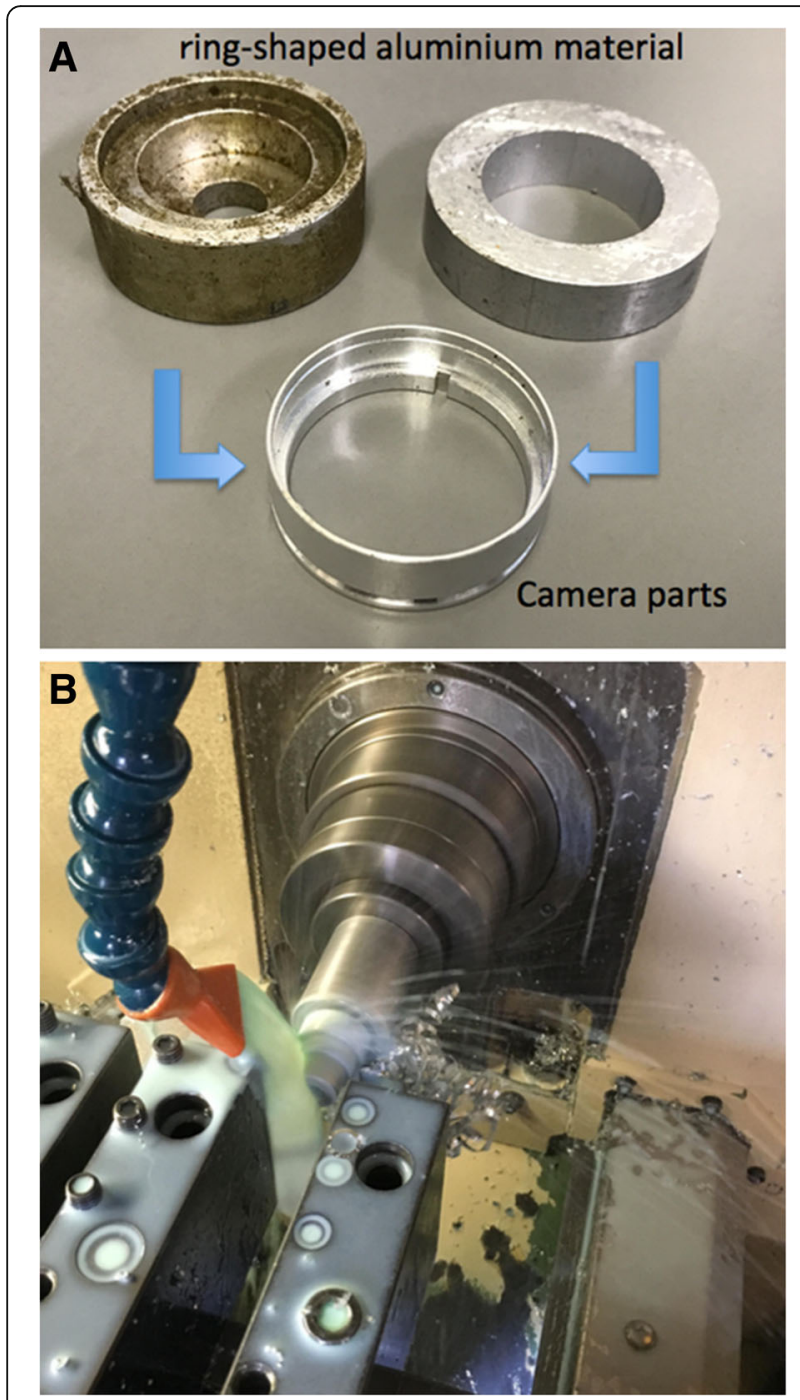

Fig. 1 The patient was engaged in shaving ring-shaped aluminum material, such as the upper 2 images, and making camera parts, like the one below (a), with a curving machine $(\mathbf{b})$. Workers are required to pour cutting oil on the material while cutting, as in (b), but our patient failed to do so, suggesting he might have inhaled a larger amount of aluminum-containing fumes than other worker in this occupation

saturation $\left(\mathrm{SpO}_{2}\right)$ of $94 \%$ on room air. Physical examination revealed fine crackles upon auscultation, especially on the bilateral upper lung areas. Otherwise, there were no abnormal physical findings. Laboratory data demonstrated elevated serum levels of Krebs von den Lungen-6 $(\mathrm{KL}-6 ; 1631 \mathrm{U} / \mathrm{mL})$ and surfactant protein D (SP-D; $157.3 \mathrm{ng} / \mathrm{mL}$ ), compared to normal values of $<500 \mathrm{U} / \mathrm{mL}$ and $<110 \mathrm{ng} / \mathrm{mL}$, respectively. Antinuclear and autologous antibodies were all negative. Chest X-ray showed linear and reticulonodular shadows with marked bilateral pleural thickening in the upper lung fields (Fig. 2). Chest CT indicated bilateral dense sub-pleural consolidation, bronchiectasis and ground glass opacities in the

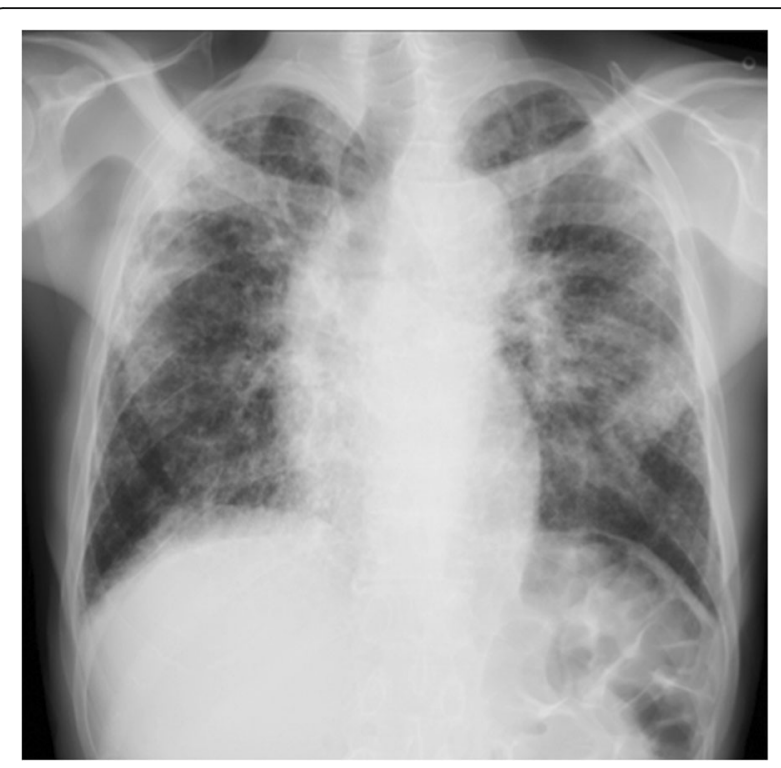

Fig. 2 Chest $X$-ray showing bilateral pleural thickening in the upper and middle lung fields. The lung volume was reduced and reticulonodular shadows extended from the sub-pleura to deep inside the lungs, suggesting pulmonary fibrosis. The tracheal bifurcation was widened by traction of the upper lobes

bilateral upper lobes (Fig. 3). Pulmonary function tests showed a restrictive disorder: vital capacity (VC) of 1.12 $\mathrm{L}$ (34.6\% of predicted), forced expiratory volume in $1.0 \mathrm{~s}$ $\left(\mathrm{FEV}_{1}\right)$ of $0.99 \mathrm{~L}$ (42.5\% of predicted), $\mathrm{FEV}_{1} / \mathrm{FVC}$ (forced vital capacity) of $74.4 \%$ and total lung capacity (TLC) of $2.48 \mathrm{~L}$ ( $47.7 \%$ of predicted). The patient was unable to perform the diffusion test correctly. TBLB was performed with bronchoscopy to get tissue samples of the right upper lobe (B2). Bronchoalveolar lavage fluid, obtained by infusing $150 \mathrm{~mL}$ of saline, revealed a total cell count of $6.0 \times 10^{4} / \mathrm{mL}$, comprised of $3 \%$ lymphocytes, $1 \%$ neutrophils, $2 \%$ eosinophils and 94\% macrophages (Cluster of Differentiation, CD 4/8 ratio of 2.31), which was in the normal range. The biopsied specimen had fragments of bronchiolar wall with infiltration of lymphocytes in interstitial spaces; unfortunately, it did not contain alveolar tissue. A surgical diagnostic procedure was avoided due to the patient's critical respiratory condition and instead, elemental analysis was performed on the existing specimen obtained by TBLB. The content of aluminum and other particles were measured in the TBLB sample.

On elemental analysis of the biopsy specimen, a relatively high amount of aluminum was detected in comparison to trace amounts of other elements, including iron and silica (Fig.4). Based on the histological findings, the elemental analysis and the occupational history, the case was diagnosed as airway aluminosis. The patient's condition was progressively getting worse; consequently, home oxygen therapy was implemented and the 

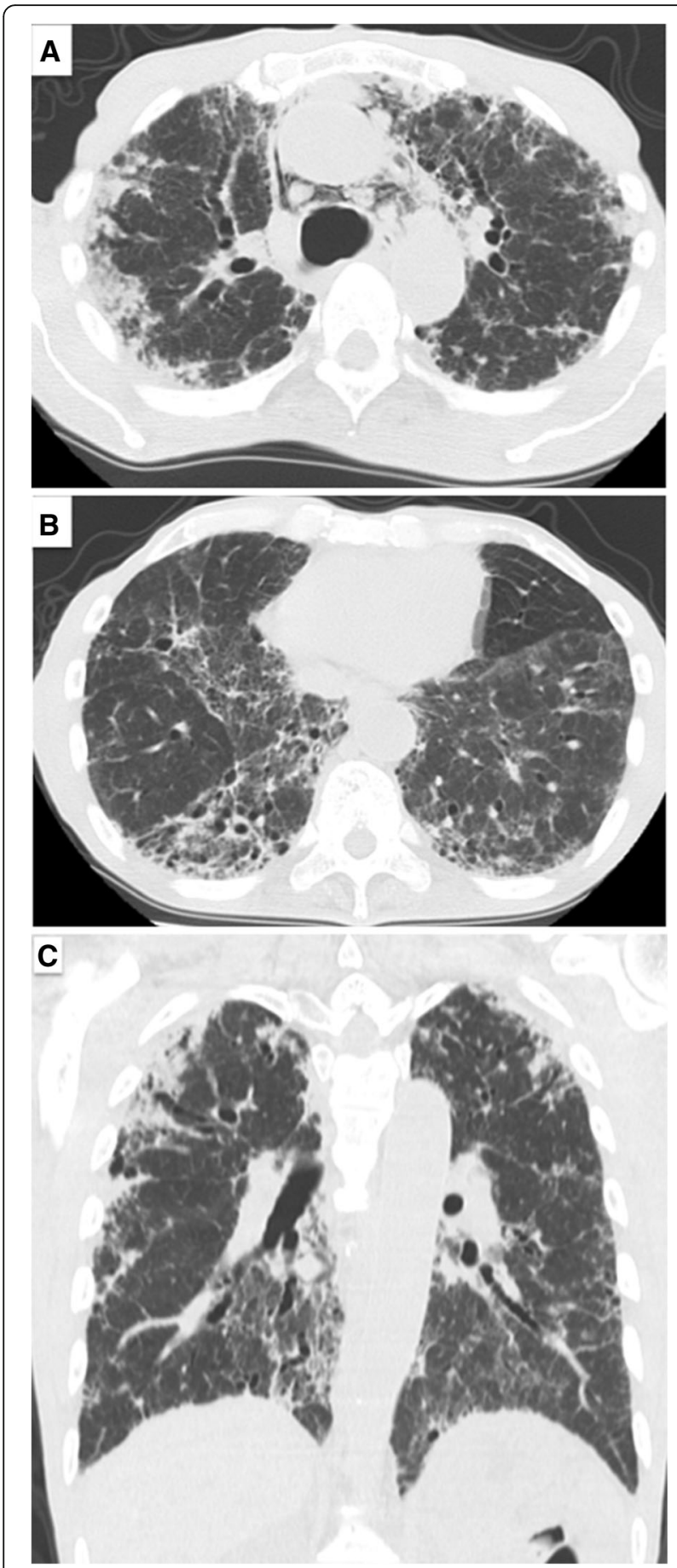

Fig. 3 High-resolution computed tomography showing severe bilateral pleural thickening with shrunken and distorted upper lobes $(\mathbf{a}, \mathbf{c})$. There was mediastinal emphysema (a). On the other hand, reticulonodular shadows and bronchiectasis were distributed deep inside the lower lung $(\mathbf{b}, \mathbf{c})$ anti-fibrotic agent pirfenidone was administered. Six months later, a pneumothorax occurred and chest drainage was performed; however, his condition deteriorated, and he died of hypercapnic respiratory failure 1 month later. His family did not agree to an autopsy.

\section{Discussion}

The etiology of PPFE has to be established yet; however, it has been suggested that dust inhalation is one of the causes of secondary PPFE [3, 4]. PPFE has been defined as upper lobe predominant sub-pleural fibrosis, with the diagnosis of PPFE needing radiological and pathological confirmation $[1,4]$.

In our case, the biopsied specimen contained only bronchiolar walls without alveolar tissue, and so did not allow histological confirmation of PPFE. Chest CT indicated upper lobe predominant pleural thickening with pulmonary fibrosis, bronchiectasis and pulmonary shrinkage, which was compatible with radiological findings for PPFE $[1,2]$. On the other hand, there were features inconsistent with PPFE, including the presence of lower lobe as well as upper lobe fibrosis and lesions deep inside the lung were observed in addition to sub-pleural fibrosis. Furthermore, typical chest CT images of PPFE reveal a clear demarcation between the abnormal and normal parts of the lung [5], while it was ill-defined in the present case. It is controversial whether reticulonodular shadows in deep areas of the lung are an element of PPFE.

Pulmonary fibrosis caused by chronic inhalation of aluminum-containing dust or fumes is known as pulmonary aluminosis [6]. Radiologically, it is usually characterized by bilateral upper lung dominant reticulonodular or irregular shadows with pleural thickening, with rare exceptions of lower lung predominance, which is sometimes the case for PPFE-like lesions [4, 7]. Histological characteristics of pulmonary aluminosis are sub-pleural fibrosis with emphysematous lesions generated by fibrotic scarring [8]. Confirming elevated levels of aluminum in alveolar tissue is required to diagnose pulmonary aluminosis $[8,9]$.

In our case, increases in serum biomarkers KL-6 and SP-D, a restrictive change in pulmonary function and radiographic findings indicated that severe pulmonary fibrosis was involved. Since an invasive procedure like surgical lung biopsy (SLB) might have exacerbated the patient's condition, we decided to only perform elemental analysis of the fragment of bronchiolar walls obtained by TBLB. This revealed an extensive deposition of aluminum, with small amounts of iron and silica, which was defined as airway aluminosis. This result indicated inhalation of large amounts of aluminium, which may have caused the PPFE-like lesions.

PPFE has a poor prognosis and effective therapies have not been identified. We administered the anti-fibrotic agent pirfenidone, which has been used for the 

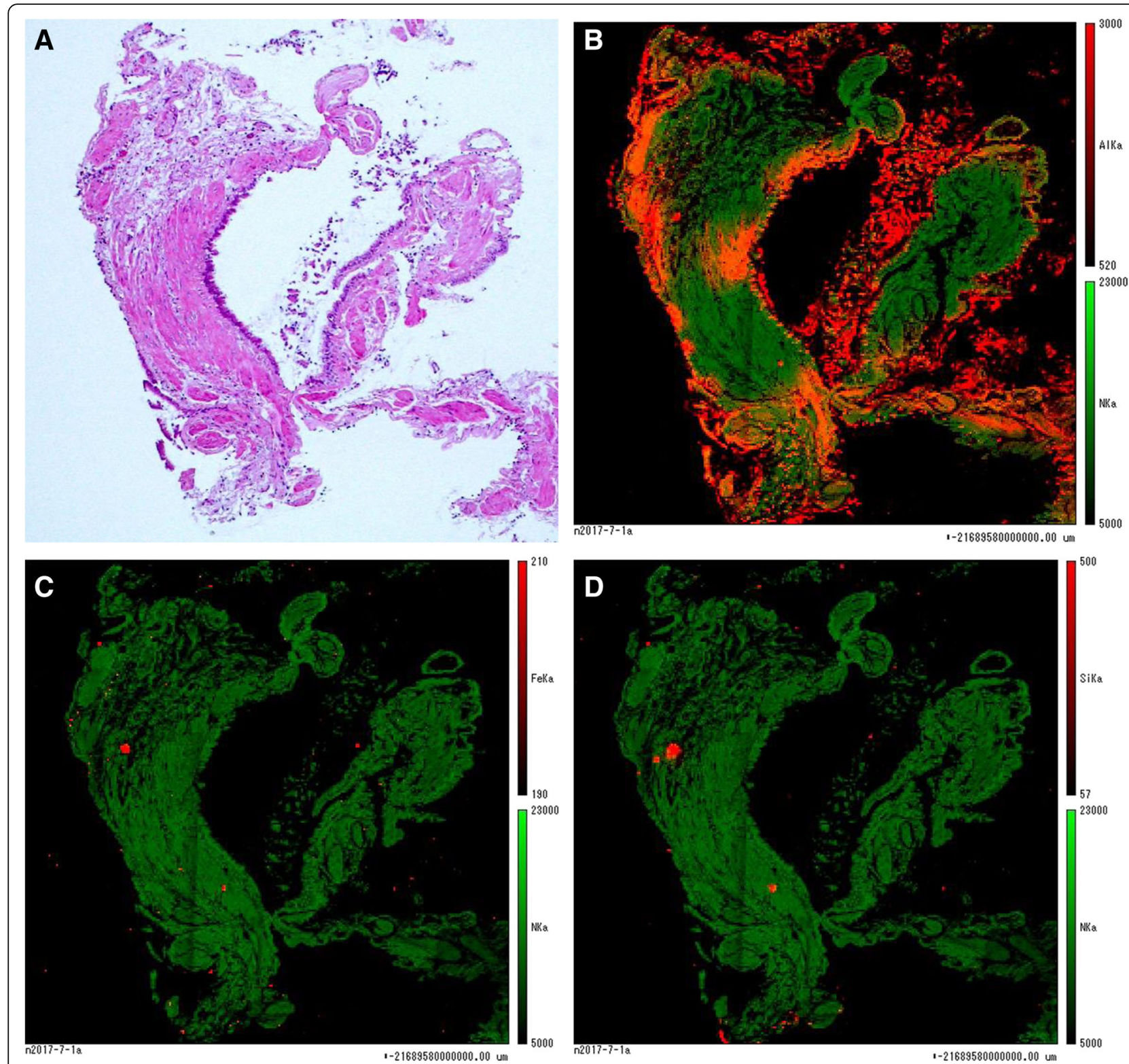

Fig. 4 Elemental analysis of the biopsy specimen by electron probe X-ray microanalysis (EPMA). Aluminum was identified in a fragment of bronchial wall obtained by trans-bronchial lung biopsy (TBLB), after staining with hematoxylin and eosin (a). Deposition of elements in the specimen was shown by red to yellow colours. The green colour indicated deposition of nitrogen as a control. Significant amounts of aluminum were identified by EPMA as shown by red to yellow colours (b), whereas iron and silica were detected in much lower amounts compared with aluminum $(\mathbf{c}, \mathbf{d})$

treatment of idiopathic pulmonary fibrosis (IPF). There is no evidence on the efficacy of pirfenidone in fibrotic lung diseases other than IPF; however, a study evaluating its efficacy is ongoing. In our case, dyspnea was not improved for 6 months after introducing pirfenidone, when pneumothorax occurred and the patient died.

As in this case, it may be worth considering TBLB in cases of secondary PPFE-like lesions that are associated with dust exposure. Patients diagnosed as secondary
PPFE with dust exposure might use the findings to obtain financial compensation.

\section{Conclusion}

This case report described upper lobe predominant lung fibrosis in an aluminium welder. It indicated that excessive inhalation of alminium might cause secondary PPFE. 


\section{Abbreviations}

CD: Cluster of Differentiation; CT: Computed tomography; FEV ${ }_{1}$ : Forced expiratory volume in $1.0 \mathrm{~s}$; FVC: Forced vital capacity; IIPs: Idiopathic interstitial pneumonias; IPPFE: Idiopathic pleuroparenchymal fibroelastosis; KL-6: Krebs von den Lungen-6; SLB: Surgical lung biopsy; SP-D: Surfactant protein $\mathrm{D} ; \mathrm{SpO}_{2}$ : Percutaneous oxygen saturation; TBLB: Trans-bronchial lung biopsy; TLC: Total lung capacity; VC: Vital capacity

\section{Acknowledgements}

We would like to acknowledge and thank Hiroshi Moriyama, MD,

Department of Homeostatic Regulation and Development, Niigata University Graduate School of Medical Dental Sciences, Niigata, Japan for conducting the elemental analysis.

\section{Funding}

Not applicable.

\section{Availability of data and materials}

Not applicable.

\section{Authors' contributions}

All authors read and approved the final manuscript.

\section{Ethics approval and consent to participate}

This study was approved by the ethical committee of the Ibaraki Higassi National Hospital, Japan.

\section{Consent for publication}

Written informed consent was obtained from the patient's family for publication of this case report and accompanying images. A copy of the written consent is available for review by the editor of this journal.

\section{Competing interests}

The authors state that they have no competing interests.

\section{Publisher's Note}

Springer Nature remains neutral with regard to jurisdictional claims in published maps and institutional affiliations.

\section{Author details}

'Department of Respiratory Medicine, National Hospital Organization, Ibaraki Higashi National Hospital, Ibaraki, Japan. ${ }^{2}$ Department of Medicine, Nikko Memorial Hospital, Ibaraki, Japan.

Received: 10 November 2018 Accepted: 26 February 2019

Published online: 15 April 2019

\section{References}

1. Travis WD, Costabel U, Hansell DM, King TE, Lynch DA, Nicholson AG, et al. An official American Thoracic Society/European Respiratory Society statement: update of the international multidisciplinary classification of the idiopathic interstitial pneumonias. Am J Respir Crit Care Med. 2013;188:733-48.

2. von der Thüsen $\mathrm{JH}$. Pleuroparenchymal fibroelastosis: its pathological characteristics. Curr Respir Med Rev. 2013;9:238-47.

3. Huang Z, Li S, Zhu Y, Zhu H, Yi X. Pleuroparenchymal fibroelastosis associated with aluminosilicate dust: a case report. Int J Clin Exp Pathol. 2015;8:8676-9.

4. Watanabe K. Pleuroparenchymal fibroelastosis: its clinical characteristics. Curr Respir Med Rev. 2013;9:229-37.

5. Bonifazi M, Montero MA, Renzoni EA. Idiopathic pleuroparenchymal fibroelastosis. Curr Pulmonol Rep. 2017;6:9-15.

6. Chino H, Hagiwara E, Sugisaki M, Baba T, Koga Y, Hisada T, et al. Pulmonary aluminosis diagnosed with in-air microparticle induced $\mathrm{X}$-ray emission analysis of particles. Intern Med. 2015;54:2035-40.

7. Smolkova P, Nakladalova M. The etiology of occupational pulmonary aluminosis - the past and the present. Biomed Pap Med Fac Univ Palacky Olomouc Czech Repub. 2014;158:535-8.

8. Kraus T, Schaller KH, Angerer J, Hilgers RD, Letzel S. Aluminosis - detection of an almost forgotten disease with HRCT. J Occup Med Toxicol. 2006;1:4.

9. Yasui M. Aluminum lung. Jpn Chest Dis. 2011;70:1249-58.

Ready to submit your research? Choose BMC and benefit from:

- fast, convenient online submission

- thorough peer review by experienced researchers in your field

- rapid publication on acceptance

- support for research data, including large and complex data types

- gold Open Access which fosters wider collaboration and increased citations

- maximum visibility for your research: over $100 \mathrm{M}$ website views per year

At BMC, research is always in progress.

Learn more biomedcentral.com/submissions 